Article

\title{
Influence of Intestinal Microbiota Transplantation and NleH Expression on Citrobacter rodentium Colonization of Mice
}

\author{
Gaochan Wang, Leigh Ann Feuerbacher and Philip R. Hardwidge * \\ Department of Diagnostic Medicine/Pathobiology, Kansas State University, Manhattan, KS 66506, USA; \\ gaochan.wang@gmail.com (G.W.); feuerbac@vet.k-state.edu (L.A.F.) \\ * Correspondence: hardwidg@vet.k-state.edu
}

Received: 6 March 2018; Accepted: 27 March 2018; Published: 30 March 2018

\begin{abstract}
The intestinal microbiota plays an important role in regulating host resistance to enteric pathogens. The relative abundance of the microbiota is dependent upon both genetic and environmental factors. The attaching and effacing pathogens enteropathogenic Escherichia coli, enterohemorrhagic E. coli, and Citrobacter rodentium cause diarrheal disease and translocate type III secretion system effector proteins into host cells to inhibit pro-inflammatory host responses. Here we determined the influence of both the intestinal microbiota and the expression of the C. rodentium $\mathrm{NleH}$ effector on $C$. rodentium colonization in different mouse models. We performed fecal transplantation experiments between C57BL/6J and C57BL/10ScNJ mice and found that such microbiota transfers altered both the host resistance to $C$. rodentium infection as well as the benefit or detriment of expressing $\mathrm{NleH}$ to $\mathrm{C}$. rodentium intestinal colonization.
\end{abstract}

Keywords: Citrobacter; colonization; microbiota

\section{Introduction}

Enteropathogenic Escherichia coli (EPEC), enterohemorrhagic Escherichia coli (EHEC), and Citrobacter rodentium are attaching and effacing (A/E) bacterial pathogens that cause infectious diarrhea [1]. EPEC and EHEC are human pathogens, while $C$. rodentium colonizes mice and is used as a model organism for in vivo studies of A/E pathogens [2]. These organisms use a type III secretion system to translocate effector proteins into host cells [3]. Some of these effectors inhibit the activation of host pro-inflammatory responses to infection by targeting regulatory components of the NF-KB signaling pathway [4].

We characterized the activity of the NleH effector and its role in C. rodentium virulence [5-8]. NleH inhibits the NF-KB pathway by preventing the phosphorylation of the ribosomal protein S3 (RPS3) via the inhibitor KB kinase beta (IKK $\beta$ ) [8]. RPS3 has a moonlighting function as an NF-KB subunit that guides the NF-KB complex to specific promoters and thus plays an important role in transcriptional activation [9]. RPS3 must be phosphorylated on serine 209 and $\mathrm{NleH}$ inhibits this phosphorylation and thus reduces RPS3 nuclear translocation [8].

Both C57BL/6J and C57BL/10ScNJ mice have been used to study the role of Toll-like receptor 4 (TLR4) in host responses to C. rodentium infection [10]. We previously observed that C. rodentium colonization of C57BL/6J mice was reduced $\sim 50$-fold upon deleting NleH [5]. When we infected C57BL/10ScNJ mice, which differ from C57BL/6J mice because they have a deletion of the Tlr4 gene and are thus not responsive to bacterial lipopolysaccharide (LPS), we observed that expressing NleH was detrimental to $C$. rodentium colonization [5]. Host inflammation appeared to contribute to this phenotype because pre-treating C57BL/10ScNJ mice with dextran sodium sulfate, which induces acute colitis in mice [11], restored the expected benefit of expressing NleH to C. rodentium [5]. 
The intestinal microbiota promotes the maturation of immune cells and the development of immunity [12]. Germ-free mice have reduced levels of secretory IgA, defects in the development of gut-associated lymphoid tissues, as well as smaller Peyer's patches and mesenteric lymph nodes [13]. Germ-free mice are more susceptible to enteric pathogens such as Shigella flexneri, C. rodentium, Listeria monocytogenes, and Salmonella enterica serovar Typhimurium [14]. Gut microbiota-mediated control of enteric pathogens is attributed to direct inhibition, barrier maintenance, immune modulation, and altered metabolism. The transplantation of gut microbiota from $\mathrm{C} 3 \mathrm{H} / \mathrm{HeJ}$ mice that are susceptible to $C$. rodentium infection induces a similar susceptibility to NIH Swiss mice that are otherwise resistant to C. rodentium infection by affecting the production of interleukin 22 (IL-22) and antimicrobial peptides [15].

Here we sought to determine both the extent to which the intestinal microbiota differ between C57BL/6J and C57BL/10ScNJ mice and whether these differences account for the previously observed [5] benefit or detriment of $C$. rodentium expressing $\mathrm{NleH}$ in these infection models.

\section{Results}

\subsection{C. rodentium Colonization Phenotypes}

We first quantified the abundance of wild-type (WT) and $\Delta n l e H$ C. rodentium in C57BL/6J mice 14 days after infection. As expected from previous studies [5,7], the colonization of $\Delta n l e H$ $\left(5.2 \pm 2.0 \times 10^{7} \mathrm{CFUs} / \mathrm{g}\right.$ colon) was significantly less than that of WT $\left(1.1+0.3 \times 10^{9} \mathrm{CFUs} / \mathrm{g}\right.$ colon $)$ (Figure 1A). We observed the opposite phenotype, as expected from previous studies [5], when we infected C57BL/10ScNJ mice. In C57BL/10ScNJ mice, the colonization of $\Delta$ nleH $\left(1.3 \pm 0.3 \times 10^{9} \mathrm{CFUs} / \mathrm{g}\right.$ colon) was significantly greater than that of WT $\left(4.6 \pm 0.8 \times 10^{7} \mathrm{CFUs} / \mathrm{g}\right.$ colon $)$ (Figure 1B). Thus, while expressing NleH is beneficial to C. rodentium colonization of C57BL/6J mice, it is detrimental to $C$. rodentium colonization of C57BL/10ScNJ mice.

A

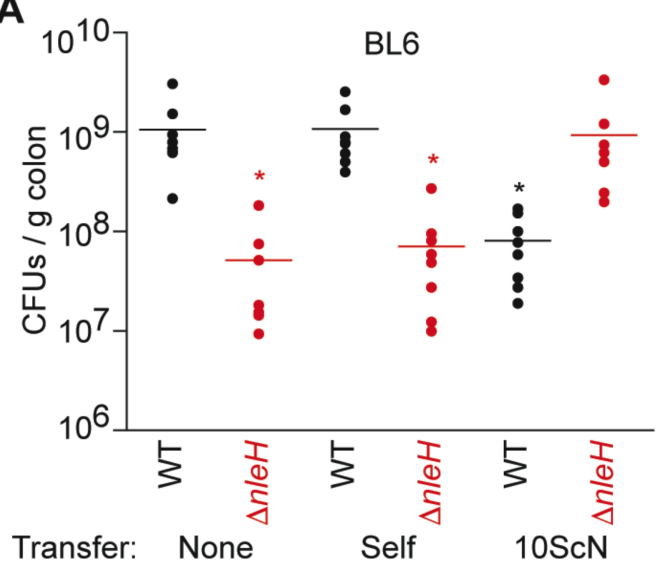

B

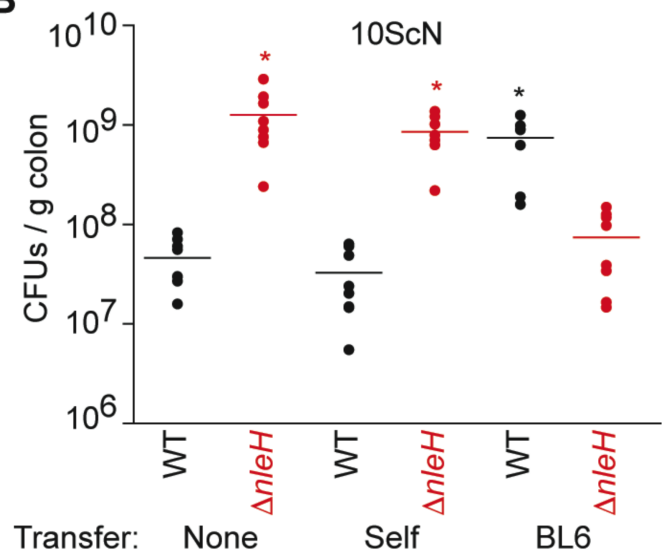

Figure 1. C. rodentium colonization as a function of fecal transplantation. (A) C. rodentium colonization of C57BL/6J mice 14 days post-infection. Where indicated, mice were first transplanted with fecal extracts from either C57BL/6J (self) or C57BL/10ScNJ $(10 \mathrm{ScN})$ mice; (B) C. rodentium colonization of $\mathrm{C} 57 \mathrm{BL} / 10 \mathrm{ScNJ}$ mice 14 days post-infection. Where indicated, mice were first transplanted with fecal extracts from either C57BL/10ScNJ (self) or C57BL/6J (BL6) mice. Asterisks indicate significantly different colonization magnitude (Kruskal-Wallis test; $p<0.05$ ) as compared with wild-type (WT) C. rodentium colonization without fecal transplantation.

To determine if the mouse intestinal microbiota plays a role in conferring this phenotype, we performed fecal transplantation experiments. We observed that while transferring microbiota within identical strains of mice had no impact on C. rodentium colonization, transferring 
microbiota between differing strains of mice reversed the colonization phenotypes between WT and $\triangle$ nleH C. rodentium (Figure 1).

\subsection{Fecal Transplantation}

To determine the extent to which fecal transplantation affected the microbiota composition of recipient mice, we used $16 \mathrm{~S}$ rDNA sequencing to determine the relative abundance of the microbial communities [16]. We then focused our analyses on the five most abundant bacterial families: Porphyromonadaceae, Prevotellaceae, Rikenellaceae, Lachnospiraceae, and Ruminococcaceae. The Prevotellaceae are anaerobic Gram-negative rods that have been isolated from human feces [17]. There is an increased abundance of Prevotella spp. in the mucosa-associated bacteria from patients with active ulcerative colitis compared to those without inflammatory bowel disease [18]. The Porphyromonadaceae are components of the gastrointestinal tract whose abundance has been associated with susceptibility to Salmonella-induced colitis [19] and potential resistance to Clostridium difficile infection [20]. Rikenellaceae are anaerobic Gram-negative rods that are increased in abundance upon Listeria monocytogenes infection [21]. The Lachnospiraceae are anaerobic bacteria that are found in human and animal digestive tracts [22]. Pre-colonization of germ-free mice with murine Lachnospiraceae are protective against $C$. difficile colonization and colonic histopathology [23]. Depletion of Ruminococcaceae has also been associated with nosocomial diarrhea and C. difficile infection [24].

Fecal transplantation from C57BL/10ScNJ mice to C57BL/6J mice resulted in a significant decrease in the abundance of Porphyromonadaceae and a significant increase in the abundance of Prevotellaceae and Rikenellaceae (Figure 2A). Fecal transplantation from C57BL/6J mice to C57BL/10ScNJ mice resulted in a significant increase in the abundance of Porphyromonadaceae and Lachnospiraceae and a significant decrease in the abundance of Prevotellaceae and Rikenellaceae (Figure 2B).
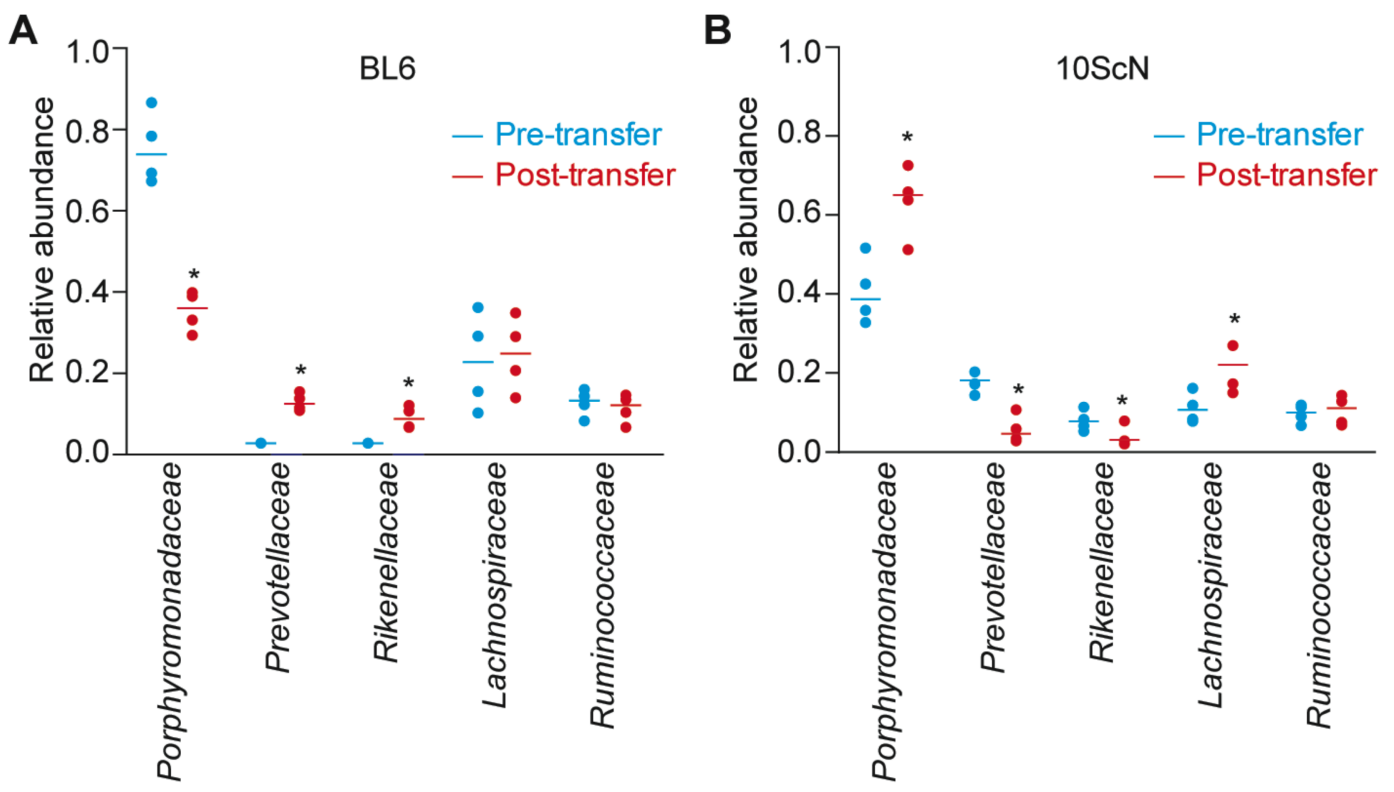

Figure 2. Relative abundance of indicated bacterial families as deduced from $16 \mathrm{~S}$ rDNA sequence annotation in C57BL/6J (A) vs. C57BL/10ScNJ mice (B). Asterisks indicate significantly different bacterial family abundance (Kruskal-Wallis test; $p<0.05$ ) as a function of transplantation of fecal contents from heterologous mouse strains.

\subsection{Microbiota Composition Shifts after C. rodentium Infection of C57BL/10ScNJ Mice}

WT C. rodentium infection of $\mathrm{C} 57 \mathrm{BL} / 10 \mathrm{ScN}$ mice resulted in a decreased abundance of Porphyromonadaceae and Prevotellaceae and an increased abundance of Lachnospiraceae, as compared to uninfected mice. By contrast, $\Delta n l e H C$. rodentium infection resulted in a decreased 
abundance only of Prevotellaceae and an increased abundance of Lachnospiraceae (Figure 3, blue and red symbols). Prior fecal transplantation from C57BL/6J mice followed by WT C. rodentium infection of C57BL/10ScNJ mice resulted in an increased abundance of Lachnospiraceae. By contrast, prior fecal transplantation from C57BL/6J mice followed by $\Delta n l e H$ C. rodentium infection resulted in no significant changes to the relative abundance of the major bacterial families in infected C57BL/10ScNJ mice (Figure 3, green and black symbols).

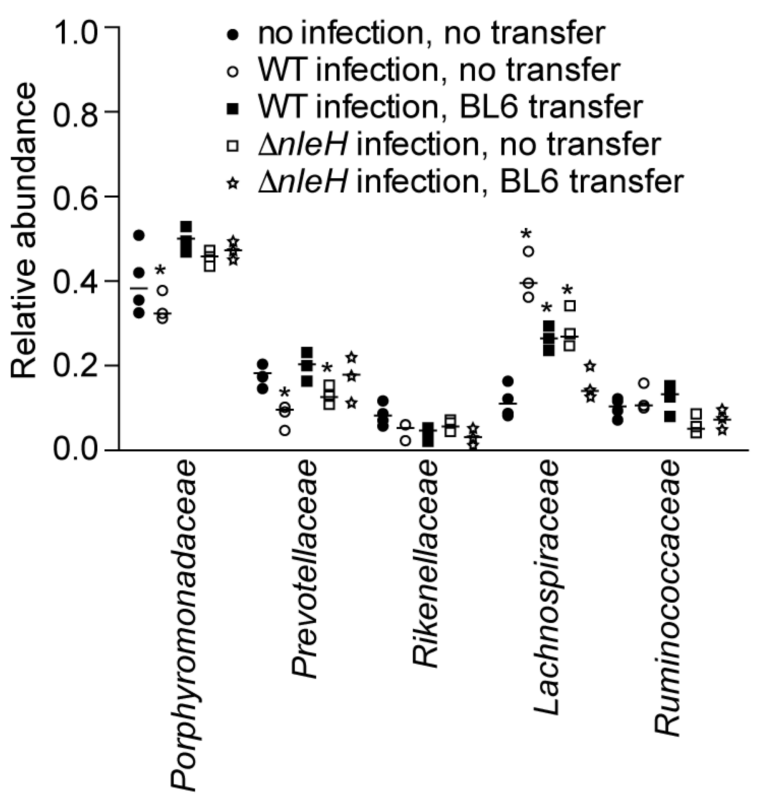

Figure 3. Relative abundance of indicated bacterial families as deduced from $16 \mathrm{~S}$ rDNA sequence annotation of C57BL6/10ScNJ mice as a function of $C$. rodentium infection and fecal transplantation from C56BL/6J mice. Asterisks indicate significantly different bacterial family abundance (Kruskal-Wallis test; $p<0.05$ ) as compared to uninfected C57BL6/10ScNJ mice.

\section{Conclusions}

We used 16S rDNA sequencing to address the composition shifts of mouse intestinal microbiomes in response to $C$. rodentium infection. We found that the Bacteroidetes and Firmicutes phyla dominated the intestinal microbiome compositions, consistent with previous findings [15]. The composition of gut microbiota varied substantially among individual mice, but major differences among bacterial families were observed between C57BL/6J and C57BL/10ScNJ mice.

Transplantation of gut microbiota from strains of mice that are susceptible to $C$. rodentium infection induces a similar susceptibility in mice that were previously resistant to $C$. rodentium infection [15]. We found that transferring the microbiota of C57BL/6J mice into C57BL/10ScNJ mice indeed altered the host susceptibility to $C$. rodentium infection and reversed the colonization phenotypes that are dependent upon $\mathrm{NleH}$ expression. We observed greater colonization of the C. rodentium $\Delta$ nleH mutant rather than the WT C. rodentium in C57BL/10ScNJ mice after fecal transplantation. These data reinforce the notion that $\mathrm{NleH}$ expression can have beneficial or detrimental impact to $C$. rodentium, depending upon the relative abundance of specific intestinal microbiota components. Our studies were limited to family-level resolution of the intestinal microbiota. Higher resolution analysis of bacteria genera that differ in abundance after $C$. rodentium infection may permit testing causal relationships between the endogenous microflora and resistance to $C$. rodentium. 


\section{Materials and Methods}

\subsection{Ethics Statement}

All animal experiments were performed in strict accordance with the guidelines of Institutional Animal Care and Use Committee at Kansas State University under protocol \#3323. This institution complies with all applicable provisions of the Animal Welfare Act and other federal statutes and regulations relating to animals.

\subsection{Mice and Fecal Transplantations}

Three to four-week-old female C57BL/6J and C57BL/10ScNJ mice were obtained from Jackson Laboratory (Bar Harbor, ME, USA). All mice were housed in sterilized cages and fed autoclaved food and water under specific-pathogen-free, controlled temperature, and controlled photoperiod conditions. Fecal transplants were performed as previously described [15]. The native microbiota was depleted by treating mice with a single oral dose $(20 \mathrm{mg} /$ mouse $)$ of streptomycin $24 \mathrm{~h}$ prior to the first fecal transplantation. Fresh fecal pellets from three to four donor mice were collected and placed in $1 \mathrm{~mL}$ transfer buffer (pre-reduced sterile phosphate buffered saline containing 0.05\% cysteine $\mathrm{HCl}$ ) on ice. Fecal pellets were homogenized and centrifuged at $800 \times g$ for 2 min and the supernatant was collected and diluted (1:3) in transfer buffer. One hundred microliters of diluted fecal supernatant was introduced into recipient mice by oral gavage on six separate occasions, every $48 \mathrm{~h}$.

\subsection{C. rodentium Infections}

Wild-type and $\triangle$ nleH C. rodentium DBS100 cultures were grown overnight in LB broth and aerobically cultured with shaking $(200 \mathrm{rpm} / \mathrm{min})$ overnight at $37^{\circ} \mathrm{C}$. The cultures were diluted (1:100) into $200 \mathrm{~mL}$ LB broth and aerobically cultured with shaking $(200 \mathrm{rpm} / \mathrm{min})$ overnight at $37^{\circ} \mathrm{C}$. Cells were harvested by centrifugation at $3000 \times \mathrm{g}$ for $15 \mathrm{~min}$ at $4{ }^{\circ} \mathrm{C}$ and washed three times with $20 \mathrm{~mL}$ of ice-cold PBS. Cells were resuspended into $2 \mathrm{~mL}$ of ice-cold $1 \times$ PBS and $100-\mu \mathrm{L}$ aliquots were used to infect mice by oral gavage 2 days after the last microbiota transfer (D14). The actual infection dose was determined by plating $100-\mu \mathrm{L}$ aliquots of successive dilutions $\left(10^{-1}-10^{-8}\right)$ on LB agar. Mice were monitored twice daily for clinical signs of illness (dehydration, rectal prolapse, loss of responsiveness to stimulation, and $>20 \%$ weight loss). Colon samples (approximately $4 \mathrm{~cm}$ ) were collected and stored on ice at necropsy. Feces were removed before weighing tissue. Colon samples were homogenized in PBS, serially diluted, and plated onto MacConkey agar for $24 \mathrm{~h}$ at $37^{\circ} \mathrm{C}$.

\subsection{Fecal DNA Extraction}

Three or four fecal pellets from each mouse were collected on the day of first microbiota transfer (day 1), just prior to infection (day 14), and at euthanasia (day 28). DNA was extracted from fecal pellets by using QIAamp DNA Stool Mini Kits (Qiagen, Venlo, The Netherlands). DNA concentrations were determined by using a Nanodrop 2000 (Fisher Scientific, Waltham, MA, USA).

\subsection{Microbial Community Analysis}

Microbial community profiles were assessed by using $16 \mathrm{~S}$ ribosomal DNA sequencing (Cofactor Genomics, St. Louis, MO, USA). Genomic DNA samples from stool samples were used to perform Ion Torrent 16S Ribosomal amplicon library construction. Bacterial Microbial 16S rRNA amplicons were generated via amplification of the V4 hypervariable region of the 16S rRNA gene using single-indexed universal primers. Approximately 40,000 reads per sample were obtained in $400 \mathrm{bp}$ reads. Informatics analysis was performed as described previously [25,26], with contiguous sequences assigned to operational taxonomic units (OTUs) via de novo clustering with a criterion of 97\% nucleotide identity [25]. 


\subsection{Statistical Analyses}

Colonization data and bacterial family abundance data were analyzed using Kruskal-Wallis tests, with $p$-values $<0.05$ considered significant.

Acknowledgments: This work was supported by grant AI099002 from the National Institute of Allergy and Infectious Diseases (NIAID). Its contents are solely the responsibility of the authors and do not necessarily represent the official views of the NIAID. The funding sponsors had no role in the design of the study; in the collection, analyses, or interpretation of data; in the writing of the manuscript, and in the decision to publish the results.

Author Contributions: G.W. and L.A.F. performed the experiments. P.R.H. designed the experiments and wrote the paper.

Conflicts of Interest: The authors declare no conflict of interest.

\section{References}

1. Kaper, J.B. Pathogenic Escherichia coli. Int. J. Med. Microbiol. IJMM 2005, 295, 355-356. [CrossRef] [PubMed]

2. Deng, W.; Li, Y.; Vallance, B.A.; Finlay, B.B. Locus of enterocyte effacement from Citrobacter rodentium: Sequence analysis and evidence for horizontal transfer among attaching and effacing pathogens. Infect. Immun. 2001, 69, 6323-6335. [CrossRef] [PubMed]

3. Furniss, R.C.D.; Clements, A. Regulation of the locus of enterocyte effacement in attaching and effacing pathogens. J. Bacteriol. 2018, 200. [CrossRef] [PubMed]

4. Gao, X.; Wang, X.; Pham, T.H.; Feuerbacher, L.A.; Lubos, M.L.; Huang, M.; Olsen, R.; Mushegian, A.; Slawson, C.; Hardwidge, P.R. Nleb, a bacterial effector with Glycosyltransferase activity, targets GAPDH function to inhibit NF-kappaB activation. Cell Host Microbe 2013, 13, 87-99. [CrossRef] [PubMed]

5. Feuerbacher, L.A.; Hardwidge, P.R. Influence of NleH effector expression, host genetics, and inflammation on Citrobacter rodentium colonization of mice. Microbes Infect. Inst. Pasteur 2014, 16, 429-433. [CrossRef] [PubMed]

6. Gao, X.; Wan, F.; Mateo, K.; Callegari, E.; Wang, D.; Deng, W.; Puente, J.; Li, F.; Chaussee, M.S.; Finlay, B.B.; et al. Bacterial effector binding to ribosomal protein S3 subverts NF-kappaB function. PLoS Pathog. 2009, 5, e1000708. [CrossRef] [PubMed]

7. Pham, T.H.; Gao, X.; Tsai, K.; Olsen, R.; Wan, F.; Hardwidge, P.R. Functional differences and interactions between the E. coli type III secretion system effectors NleH1 and NleH2. Infect. Immun. 2012, 80, 2133-2140. [PubMed]

8. Wan, F.; Weaver, A.; Gao, X.; Bern, M.; Hardwidge, P.R.; Lenardo, M.J. IKKbeta phosphorylation regulates RPS3 nuclear translocation and NF-kappaB function during infection with Escherichia coli strain O157:H7. Nat. Immunol. 2011, 12, 335-343. [CrossRef] [PubMed]

9. Wan, F.; Anderson, D.E.; Barnitz, R.A.; Snow, A.; Bidere, N.; Zheng, L.; Hegde, V.; Lam, L.T.; Staudt, L.M.; Levens, D.; et al. Ribosomal protein S3: A KH domain subunit in NF-kappaB complexes that mediates selective gene regulation. Cell 2007, 131, 927-939. [CrossRef] [PubMed]

10. Khan, M.A.; Ma, C.; Knodler, L.A.; Valdez, Y.; Rosenberger, C.M.; Deng, W.; Finlay, B.B.; Vallance, B.A. Toll-like receptor 4 contributes to colitis development but not to host defense during Citrobacter rodentium infection in mice. Infect. Immun. 2006, 74, 2522-2536. [CrossRef] [PubMed]

11. Ivison, S.M.; Himmel, M.E.; Hardenberg, G.; Wark, P.A.; Kifayet, A.; Levings, M.K.; Steiner, T.S. TLR5 is not required for flagellin-mediated exacerbation of DSS colitis. Inflamm. Bowel Dis. 2010, 16, 401-409. [CrossRef] [PubMed]

12. Stecher, B.; Hardt, W.D. The role of microbiota in infectious disease. Trends Microbiol. 2008, 16, 107-114. [CrossRef] [PubMed]

13. Round, J.L.; Mazmanian, S.K. The gut microbiota shapes intestinal immune responses during health and disease. Nat. Rev. Immunol. 2009, 9, 313-323. [CrossRef] [PubMed]

14. Baumler, A.J.; Sperandio, V. Interactions between the microbiota and pathogenic bacteria in the gut. Nature 2016, 535, 85-93. [CrossRef] [PubMed]

15. Willing, B.P.; Vacharaksa, A.; Croxen, M.; Thanachayanont, T.; Finlay, B.B. Altering host resistance to infections through microbial transplantation. PLoS ONE 2011, 6, e26988. [CrossRef] [PubMed] 
16. Caporaso, J.G.; Lauber, C.L.; Walters, W.A.; Berg-Lyons, D.; Lozupone, C.A.; Turnbaugh, P.J.; Fierer, N.; Knight, R. Global patterns of $16 \mathrm{~s}$ rRNA diversity at a depth of millions of sequences per sample. Proc. Natl. Acad. Sci. USA 2011, 108, 4516-4522. [CrossRef] [PubMed]

17. Morotomi, M.; Nagai, F.; Sakon, H.; Tanaka, R. Paraprevotella clara gen. Nov., sp. Nov. And Paraprevotella xylaniphila sp. Nov., members of the family 'Prevotellaceae' isolated from human faeces. Int. J. Syst. Evol. Microbiol. 2009, 59, 1895-1900. [CrossRef] [PubMed]

18. Lucke, K.; Miehlke, S.; Jacobs, E.; Schuppler, M. Prevalence of Bacteroides and Prevotella spp. In ulcerative colitis. J. Med. Microbiol. 2006, 55, 617-624. [CrossRef] [PubMed]

19. Ferreira, R.B.; Gill, N.; Willing, B.P.; Antunes, L.C.; Russell, S.L.; Croxen, M.A.; Finlay, B.B. The intestinal microbiota plays a role in Salmonella-induced colitis independent of pathogen colonization. PLOS ONE 2011, 6, e20338. [CrossRef] [PubMed]

20. Schubert, A.M.; Sinani, H.; Schloss, P.D. Antibiotic-induced alterations of the murine gut microbiota and subsequent effects on colonization resistance against Clostridium difficile. MBio 2015, 6, e00974. [CrossRef] [PubMed]

21. Ji, Z.H.; Ren, W.Z.; Gao, W.; Hao, Y.; Gao, W.; Chen, J.; Quan, F.S.; Hu, J.P.; Yuan, B. Analyzing the innate immunity of $\mathrm{NIH}$ hairless mice and the impact of gut microbial polymorphisms on Listeria monocytogenes infection. Oncotarget 2017, 8, 106222-106232. [CrossRef] [PubMed]

22. Hedberg, M.E.; Moore, E.R.; Svensson-Stadler, L.; Horstedt, P.; Baranov, V.; Hernell, O.; Wai, S.N.; Hammarstrom, S.; Hammarstrom, M.L. Lachnoanaerobaculum gen. Nov., a new genus in the Lachnospiraceae: Characterization of Lachnoanaerobaculum umeaense gen. Nov., sp. Nov., isolated from the human small intestine, and Lachnoanaerobaculum orale sp. Nov., isolated from saliva, and reclassification of eubacterium saburreum (prevot 1966) holdeman and moore 1970 as Lachnoanaerobaculum saburreum comb. Nov. Int. J. Syst. Evol. Microbiol. 2012, 62, 2685-2690. [PubMed]

23. Reeves, A.E.; Koenigsknecht, M.J.; Bergin, I.L.; Young, V.B. Suppression of Clostridium difficile in the gastrointestinal tracts of germfree mice inoculated with a murine isolate from the family Lachnospiraceae. Infect. Immun. 2012, 80, 3786-3794. [CrossRef] [PubMed]

24. Antharam, V.C.; Li, E.C.; Ishmael, A.; Sharma, A.; Mai, V.; Rand, K.H.; Wang, G.P. Intestinal dysbiosis and depletion of butyrogenic bacteria in Clostridium difficile infection and nosocomial diarrhea. J. Clin. Microbiol. 2013, 51, 2884-2892. [CrossRef] [PubMed]

25. Hart, M.L.; Meyer, A.; Johnson, P.J.; Ericsson, A.C. Comparative evaluation of DNA extraction methods from feces of multiple host species for downstream next-generation sequencing. PLoS ONE 2015, 10, e0143334. [CrossRef] [PubMed]

26. Hays, M.P.; Ericsson, A.C.; Yang, Y.; Hardwidge, P.R. Vaccinating with conserved Escherichia coli antigens does not alter the mouse intestinal microbiome. BMC Res. Notes 2016, 9, 401. [CrossRef] [PubMed]

(c) 2018 by the authors. Licensee MDPI, Basel, Switzerland. This article is an open access article distributed under the terms and conditions of the Creative Commons Attribution (CC BY) license (http:/ / creativecommons.org/licenses/by/4.0/). 